\title{
CONVENÇÕES DE QUALIDADE EM QUEIJOS ARTESANAIS NO BRASIL, ESPANHA E ITÁLIA
}

\section{Quality conventions in artisanal cheeses in Brazil, Spain and Italy}

\author{
Bruna Bresolin Roldan ${ }^{1}$, Jean Philippe Palma Revillion ${ }^{1}$
}

\begin{abstract}
RESUMO
Muitas vezes os alimentos artesanais são vistos pelos consumidores como sendo mais naturais e saudáveis e são valorizados devido a sua tradição, origem e sustentabilidade dos processos envolvidos. Os queijos artesanais representam bem essa categoria de alimentos, pois sua caracterização envolve o tipo de matéria-prima, o método de processamento, as características edafoclimáticas de onde são produzidos, as receitas utilizadas, a pequena escala de produção, as relações estabelecidas entre o produtor e o consumidor. No entanto, essas características estão balizadas por normas sanitárias que nem sempre conseguem ser atendidas pelos produtores, que acabam por realizar a venda informalmente. O objetivo deste artigo é demonstrar as diferenças existentes entre as concepções, práticas e estratégias de qualidade de queijos artesanais e o impacto da legislação sanitária sobre eles a partir de estudos de caso específicos de queijarias do Brasil, Espanha e Itália.

Palavras-chave: agroindústria familiar; Teoria das Convenções; certificação.
\end{abstract}

\begin{abstract}
Artisanal foods are often seen by consumers as being more natural and healthier, and they are valued for their tradition, origin and the sustainability of the processes involved. Artisanal cheeses well represent this category of food, as their characterization involves the type of raw material, the processing method, the edaphoclimatic characteristics from which they are produced, the recipes used, the small scale of production, the relationships established between the producer and
\end{abstract}

1 Universidade Federal do Rio Grande do Sul, Campus do Vale, Instituto de Ciência e Tecnologia de Alimentos, Avenida Bento Gonçalves, 9500, Prédio 43.212, 91501-970, Porto Alegre, RS, Brasil.

E-mail:brunabre@gmail.com

* Autor para correspondência.

Recebido / Received: 27/02/2019

Aprovado / Approved: 06/05/2019 
the consumer. However, these characteristics are governed by sanitary standards that are not always followed by producers, who therefore sell their products informally. The aim of this paper is to describe the differences between the concepts, practices and strategies of quality of artisanal cheeses and the impact of sanitary legislation on them from specific case studies of Brazilian, Spanish and Italian artisanal cheese factories.

Keywords: family agribusiness; Convention Theory; certification.

\section{INTRODUÇÃO}

A importância atribuída pelos consumidores à qualidade dos alimentos tem aumentado nos últimos anos, envolvendo tanto atributos intrínsecos, como teores de gordura e sal, quanto atributos extrínsecos, como sua origem geográfica e natureza do método de processamento, grau de sustentabilidade dos processos envolvidos, inocuidade do alimento (GRUNERT, 2005; STAMER, 2018).

Essas dimensões extrínsecas refletem valores e atitudes dos consumidores e subsidiaram um movimento chamado de "qualityturn", que proporcionou a valorização de alimentos "artesanais", "naturais", "oriundos direto do produtor", "locais", muitas vezes tidos como mais saudáveis pelos consumidores (GOODMAN, 2003, 2004). O resultado desse movimento tem levado a uma importância crescente da transparência e ética nas redes agroalimentares, fazendo com que as práticas de garantia de qualidade e rastreabilidade que balizam a certificação (formal ou informal) relacionada à origem geográfica e a produção orgânica, por exemplo, sejam validadas através de mecanismos baseados no relacionamento direto entre produtor e consumidor, gerando relações de confiança e fidelidade (NICHELE; WAQUIL, 2011; VIEIRA et al., 2013; DIAS, 2016; PONTE, 2016).

Nesses setores alimentícios onde predominam dimensões de qualidade extrínsecas, cuja avaliação é subjetiva e realizada a partir da visão de mundo de cada consumidor, a qualidade é então concebida como uma con- venção social, resultado de um acordo coletivo, por meio do qual os atores conseguem se entender em uma determinada cena de mercado (NIEDERLE, 2013). Assim, não há uma compreensão universal da qualidade, pois a qualidade é avaliada através da interação social, de diferentes maneiras, dependendo de que convenções são utilizadas para justificar essa avaliação e todas as ações prévias necessárias à produção, processamento e oferta dos alimentos (EYMARD-DUVERNAY, 1989).

A categoria dos queijos artesanais tipicamente representa um produto que é valorizado a partir de atributos extrínsecos como utilização de leite cru, as características particulares do leite em função da tipicidade das condições edafoclimáticas do local de produção, das práticas de produção adotadas e das espécies e raças de animais do rebanho, uso de métodos manuais, práticas e formulações tradicionais na elaboração dos queijos, a presença de fermentos lácteos autóctones, atribuindo características sensoriais únicas ao produto, pequena escala de produção, reputação do produtor, realização de venda direta (STEENKAMP, 1990; GRUNERT, 2005; ZUMBO et al., 2009; CRUZ; MENASCHE, 2014; SEIXAS et al., 2014; GONZÁLEZ-CÓRDOVA et al., 2016).

De outro lado, esses produtos também são avaliados a partir de indicadores intrínsecos de natureza físico-química (teor de gordura e umidade, por exemplo) e microbiológica (controle de microrganismos patogênicos e deterioradores, por exemplo) em função de normas sanitárias e classifi- 
catórias (atribuindo-lhe uma categoria ou variedade) que os submetem a um esforço de padronização - a exigência de pasteurização do leite é a representação típica da busca de uma matéria-prima standard (KNOLL, 2005).

Os trade-off relacionados à busca de diversidade e tipicidade versus a busca de padronização e garantia de inocuidade são mediados pela legislação sanitária dessa categoria de produtos, que é específica de cada país. Por exemplo, na legislação brasileira, os queijos devem ser produzidos com leite pasteurizado, com exceção dos queijos que apresentam, no mínimo, sessenta dias de maturação, ou quando estudos técnico-científicos comprovarem que a redução do período de maturação não compromete a qualidade e a inocuidade do produto. Porém, a redução no tempo de maturação fica restrita a queijaria situada em região de indicação geográfica registrada ou tradicionalmente reconhecida e em propriedade certificada como livre de tuberculose e brucelose (BRASIL, 1996, 2013).

A União Europeia permite a comercialização de queijos de leite cru, independentemente do tempo de maturação, porém a produção de alimentos deve implementar controles na produção, que vão desde a saúde do rebanho até as etapas finais de produção e comercialização, baseados na adoção do programa de Análise de Perigos e Pontos Críticos de Controle (PARLAMENTO EUROPEO Y DEL CONSEJO, 2004a,b,c, 2005).

O objetivo deste artigo é demonstrar as diferenças existentes entre as concepções, práticas e estratégias de qualidade de queijos artesanais e o impacto da legislação sanitária sobre eles a partir de estudos de caso específicos de queijarias do Brasil, Espanha e Itália.

\section{MATERIAL E MÉTODOS}

Nessa pesquisa foi aplicado o método de estudo de caso, que foram selecionados para investigar um fenômeno contemporâneo, em seu contexto real, através do uso de entrevistas semiestruturadas, consulta a dados secundários e observação direta (YIN, 2001).

Durante o período de agosto a setembro de 2018 foram realizadas entrevistas semiestruturadas com produtores de queijo artesanal no estado do Rio Grande do Sul e técnicos que trabalham com o setor, como extensionistas rurais ou definidores de políticas públicas da Secretaria Estadual de Agricultura, Pecuária e Desenvolvimento Rural e do Ministério da Agricultura, Pecuária e Abastecimento. No período de outubro de 2018 a fevereiro de 2019 foram realizadas entrevistas com produtores da região do Vêneto, na Itália - região que possui Denominação de Origem para o queijo Asiago - e produtores de queijos artesanais de leite de cabra e ovelha na Espanha e técnicos da Rede espanhola de queijarias de campo e artesanais (Quered) e do Instituto de Investigação e Formação Agrária e Pesqueira da Junta de Andaluzia (IFAPA).

A escolha dos casos brasileiros foi baseada na participação dos produtores no Programa Estadual de Agroindústria Familiar do Rio Grande do Sul e no tipo de queijo produzido, além de contemplar a produção formal e informal. Os casos espanhóis e italianos buscaram contemplar a maior diversidade de produtores e também foi baseada na disponibilidade das empresas em participar da pesquisa.

As questões que compuseram a entrevista semiestruturada foram agrupadas em: caracterização da agroindústria, tipo de relações com clientes, particularidades do processamento, aspectos diferenciais da qualidade dos produtos e impacto da legislação sobre esses fatores. As entrevistas foram gravadas e posteriormente transcritas. A análise dos dados foi realizada com apoio do software NVivo12. 


\section{RESULTADOS E DISCUSSÃO}

\section{O Conceito de Queijo Artesanal}

Quando questionados sobre o que era um queijo artesanal, a opinião de técnicos e produtores de todos os países estavam orientadas no mesmo sentido, ou seja, consideram um queijo artesanal de qualidade aquele que possui qualidade higiênicosanitária, cumprindo os requisitos de boas práticas agropecuárias e boas práticas de fabricação. Dentre esses aspectos, a qualidade do leite foi um item reforçado por vários entrevistados. E claro que a qualidade também está relacionada às características sensoriais de cada tipo de queijo.

Uma das grandes diferenças observadas entre os entrevistados brasileiros e europeus foi em relação à qualidade versus preço. Os produtores europeus relataram que os consumidores valorizam o queijo artesanal, ou seja, querem conhecer a origem do produto, o produtor, os animais e valorizam a tradição - afirmaram também que o consumidor compra porque valoriza a qualidade do queijo artesanal e o seu sabor. Em relação ao preço, na Espanha os produtores já entendem que aquele consumidor que busca somente preço, está na verdade buscando um queijo industrial e não está valorizando o produto artesanal e na Itália todos os produtores afirmaram que seus clientes não estão focados no preço e sim na qualidade do queijo.

Já a maioria dos produtores brasileiros afirmou que grande parte dos consumidores buscam preço. O que pode ser justificado pelo fato de que no Brasil o comércio de queijos artesanais muitas vezes se relaciona com a venda informal destes produtos, sendo muitas vezes mais baratos que os produtos industrializados encontrados no supermercado. Porém, uma minoria de produtores relatou que os consumidores que valorizam a produção artesanal estão em busca de novas experiências, consideram esse tipo de produto como sendo mais saudável e buscam satisfazer sua memória afetiva - relatando que parte dos consumidores são pessoas que moravam no interior e agora estão na cidade e procuram por estes produtos que os remetem a infância, ao seu passado.

\section{O Contexto Institucional sobre o Queijo Artesanal}

No Brasil não existe uma definição única e em lei, que determine a caracterização de um alimento artesanal. Na literatura existem várias definições para queijos artesanais, que abrangem aspectos relacionados à utilização de leite cru ou pasteurizado, uso de métodos manuais, padronização, uso de receitas e formulações tradicionais, pequena escala de produção, podendo o leite ser de diferentes espécies animais, possuindo diferentes tempos de maturação e grande variedade (ZUMBO et al., 2009; CRUZ; MENASCHE, 2014; GONZÁLEZ-CÓRDOVA et al., 2016).

Os regulamentos da União Europeia a respeito das condições higiênico-sanitárias que devem ser cumpridas no processamento de alimentos, preveem a possibilidade de regulamentar em pormenor algumas atividades de acordo com a tradição, a pequena escala, o nível local, porém não trazem uma definição de alimento artesanal (PARLAMENTO EUROPEO Y DEL CONSEJO, 2004a,b,c,).

A Espanha possui uma definição de queijaria artesanal de campo, que transforma somente seu próprio leite, e queijaria artesanal, que compra leite de propriedades próximas (QUERED, 2019). Além disso, cada comunidade autônoma pode ter sua definição, além de cada regulamento com denominação de origem trazer a definição do que caracteriza aquele queijo artesanal.

Na Itália, por exemplo, a região do Vêneto possui um projeto chamado PPL (Piccole Produzione Locale) que possui regulamentos 
próprios para a pequena produção de alimentos realizada na região. O regulamento para venda de leite e derivados está relacionado a um volume máximo de litros de leite/ano que o produtor pode processar para ser considerado pequeno produtor e o queijo é definido conforme os regulamentos de denominação de origem (PICCOLE PRODUZIONI LOCALI, 2017).

O consórcio Asiago Formaggio DOP, por exemplo, define que um queijo artesanal não está relacionado com o tipo de leite (mesmo que, muito frequentemente, os queijos artesanais sejam de leite cru), mas está sim relacionado com uma série de outras características, que inclui o volume de leite processado, o método de processamento, com uma importante contribuição humana, e a falta de padronização, pois a caracterização do produto, dentro de um determinado intervalo, é sempre diferente (ASIAGO FORMAGGIO DOP, 2019).

$\mathrm{Na}$ opinião dos entrevistados, tanto produtores como técnicos, a definição de queijo artesanal deve estar relacionada à pequena escala de produção, ao processamento manual, com valorização da pessoa que realiza o processamento, que possui conhecimento e experiência e que muitas vezes são passados de pai para filho. Há contradições em relação à necessidade de a matéria-prima ser própria e sobre o uso de leite cru e, no caso dos entrevistados brasileiros sobre a necessidade da mão-de-obra ser familiar.

As opiniões em relação à padronização de produtos artesanais são diversas, no entanto, é certo que uma produção artesanal não será totalmente padronizada, pois alterações nas características da matéria-prima ocorrerão devido a alimentação dos animais, raça, estação do ano, que influenciarão o sabor do queijo, etc. (LICITRA, 2010; POZNANSKI et al., 2004). Para os produtores é importante manter uma padronização, pois todos relataram que os clientes percebem as diferenças no produto. $\mathrm{O}$ que os técnicos afirmam é que dentro de uma região produtora de queijo, vai haver uma variação entre as propriedades e uma variação dentro da propriedade, devido aos fatores já citados. Porém, é importante manter uma padronização dos ingredientes, como medidas de sal, coalho e de parâmetros de processamento, como temperatura e tempo.

Em relação ao impacto da legislação sanitária na elaboração de queijos artesanais, os produtores e técnicos brasileiros criticam a legislação por ter muitos requisitos baseados em infraestrutura, que muitas vezes exigem grandes investimentos e impedem a formalização, defendem que a legislação deveria estar baseada nas Boas Práticas Agropecuárias, como a sanidade do rebanho, implementação de Boas Práticas de Fabricação (BPF) e análises dos padrões de identidade e qualidade dos produtos finais. Uma das críticas também é em relação à falta de uma legislação específica para a produção artesanal e as adaptações que são geradas a partir do regulamento industrial, que não atendem as reais necessidades da produção artesanal.

$\mathrm{Na}$ Espanha também foram evidenciadas inadequações em relação à legislação sanitária: em 2009, os pequenos produtores de queijo artesanal formaram a QueRed (Rede spañola de queserías de campo y artesanas) para tornarem-se mais fortes e poderem defender seu ponto de vista frente a administração pública. A Europa possui um regulamento único para a produção de alimentos, conforme já descrito anteriormente. Cada país membro deve cumprir o estabelecido no regulamento e não pode legislar sobre o assunto, tornando a legislação mais restritiva. Porém, assim como relatado pelos entrevistados brasileiros, existem problemas sobre a interpretação das normas.

O que foi possível verificar durante a realização das entrevistas e pelas próprias observações dos entrevistados é que para a 
utilização de leite cru, a qualidade do leite, que sempre é importante, ganha uma importância ainda maior, principalmente em relação à sanidade do rebanho, e preocupações existentes no Brasil, como brucelose e tuberculose estão controladas ou superadas na Europa. Também se observou na Europa um maior respeito às leis sanitárias existentes e uma preocupação com o setor lácteo. Por exemplo, quando os entrevistados foram questionados a respeito da comercialização de queijos antes da obtenção do registro sanitário, todos responderam que não se pode comercializar sem estar formalizado e dois entrevistados citaram os prejuízos que a comercialização de um queijo causador de surto poderia trazer para todo o setor.
É interessante notar, como descrito pelos entrevistados e por Cruz; Menasche (2014) que apesar de haver um critério que define legalmente o período mínimo de maturação, são estabelecidos técnicas e critérios socialmente definidos e compartilhados, baseados na experiência e conhecimento local, que permitem aos produtores e consumidores elaborar critérios próprios para definição do período de maturação (CRUZ; MENASCHE, 2014).

\section{Os estudos de caso}

Os Quadros 1, 2 e 3 apresentam a caracterização dos casos estudados no Brasil, Espanha e Itália.

Quadro 1 - Caracterização dos casos brasileiros

\section{Produtor: B1}

Município: Estância Velha

Formalização: Serviço de Inspeção Municipal

Leite utilizado: Leite de vaca pasteurizado

Tipo de queijo produzido: Queijo colonial e outros derivados lácteos

Volume de leite processado/dia: $300 \mathrm{~L}$

Canais de comercialização: feiras, alimentação escolar

Principais dificuldades enfrentadas para a produção de queijo: qualidade da matériaprima e legalização sanitária

Relações com os clientes: "Tu conheces pelo nome, esse é o lado maravilhoso da feira, porque tu consegue conversar com o cliente, explicar todo o processo, eles te chamam pelo nome e tu chama eles pelo nome, eles te contam coisas da vida deles. Os clientes viajam, voltam contando sobre queijos, questionam sobre algumas coisas daqui, daí eu explico que aqui não pode, que aqui é diferente e a gente tenta fazer a coisa certa”.

Definição de queijo artesanal: predomínio de trabalho manual, uso de leite cru

Definição de qualidade: Matéria-prima de qualidade, higiene, manutenção do padrão de produção

Opinião sobre a legislação sanitária: Acredita que melhorou, porém ainda há muitas divergências entre as exigências de um serviço de inspeção municipal para outro. Relata a subjetividade dos fiscais. "A qualidade do leite tá boa, os requisitos sanitários também, livre de brucelose e tuberculose, tinha que ter uma legislação diferente, porque eles vão cobrar de mim as mesmas coisas que eles cobram de quem processa uma quantidade bem maior e adquire leite?". 
Opinião sobre a padronização do queijo: "É bem importante ter um padrão. Os clientes percebem quando o queijo está diferente". Porém, considera que possui um tipo de queijo no verão e outro no inverno, devido a alimentação das vacas, que influencia nas características do leite".

Legislação a que está submetido: normas técnicas do SIM

Produtor: B2

Município: Progresso

Formalização: Serviço de Inspeção Municipal

Leite utilizado: Leite de vaca pasteurizado

Tipo de queijo produzido: Queijo colonial

Volume de leite processado/dia: 1.050 litros

Canais de comercialização: vendem para distribuidores

Principais dificuldades enfrentadas para a produção de queijo: legalização sanitária

Relações com os clientes: não conhecem o consumidor final

Definição de queijo artesanal: formato redondo, pequena escala de produção

Definição de qualidade: o queijo deve possuir boa aparência e sabor

Opinião sobre a legislação sanitária: é difícil atender todas as exigências da legislação.

Opinião sobre a padronização do queijo: "É importante manter a padronização porque os consumidores percebem quando o produto está diferente".

Legislação a que está submetido: normas técnicas do SIM

Produtor: B3

Município: Progresso

Formalização: produtor informal

Leite utilizado: Leite de vaca cru

Tipo de queijo produzido: Queijo colonial

Volume de leite processado/dia: 40 litros

Canais de comercialização: venda direta na propriedade, encomendas

Principais dificuldades enfrentadas para a produção de queijo: qualidade da matéria-prima

Relações com os clientes: proximidade, compram com assiduidade e são fiéis

Definição de queijo artesanal: "É mais puro, saboroso, sem química".

Definição de qualidade: o queijo deve ser amarelo, não muito seco, amanteigado, redondo. "Alguns clientes querem com furos. Mas os furadinhos a gente não sabe fazer, o furadinho tem que ser um queijo mais novo".

Opinião sobre a legislação sanitária: ---

Opinião sobre a padronização do queijo: "É importante manter o padrão porque os clientes reclamam, nota a diferença”.

Produtor: B4

Município: São Francisco de Paula

Formalização: produtor informal

Leite utilizado: Leite de vaca cru 
Tipo de queijo produzido: Queijo artesanal serrano Volume de leite processado/dia: 250 litros

Canais de comercialização: supermercados, fruteiras, lancherias e venda na propriedade Principais dificuldades enfrentadas para a produção de queijo: investimento em infraestrutura, falta de padronização entre o que é solicitado pelos fiscais

Relações com os clientes: proximidade, compram com assiduidade e são fiéis

Definição de queijo artesanal: Mão-de-obra familiar, leite próprio, não necessariamente precisa ser de leite cru

Definição de qualidade: "Em primeiro lugar o leite precisa ser boa qualidade".

Opinião sobre a legislação sanitária: "Eu acho que poderia fazer análises nos queijos, se deu tudo ok, pode liberar para comercialização com menos dias de maturação." O produtor relata também as exigências em relação a infraestrutura, que demandam grandes investimentos.

Opinião sobre a padronização do queijo: "Sim, eu acho que um pouco tem que padronizar". $\mathrm{O}$ produtor relata que mede as quantidades utilizadas de coalho e sal para tentar padronizar e o cliente não reclamar de diferenças no sabor.

Produtor: B5

Município: São Francisco de Paula

Formalização: Serviço de Inspeção Municipal (SUSAF/RS)

Lei utilizado: Leite de vaca cru

Tipo de queijo produzido: Queijo artesanal serrano

Volume de leite processado/dia: 40 litros

Canais de comercialização: venda direta na propriedade, supermercados, tendas

Principais dificuldades enfrentadas para a produção de queijo: Produção e qualidade da matéria-prima, dificuldades para a legalização sanitária, mercado consumidor para o queijo maturado com 60 dias

Relações com os clientes: a maior venda é feita para intermediários

Definição de queijo artesanal: Leite cru, processo manual, maturação na tábua, lenta, sem refrigeração.

Definição de qualidade: o queijo deve ter boa apresentação, casca fina, padrão de textura e sabor.

Opinião sobre a legislação sanitária: "Quanto à legislação sanitária, no início foi difícil entender, mas faz tempo que a gente tá cuidando mais na higiene e etc. Teria que mudar a legislação para diminuir o tempo de maturação e com essa mudança, mais pessoas vão se interessar em colocar casas de queijo".

Opinião sobre a padronização do queijo: "É importante manter a padronização, o cliente aperta com o dedo para ver se o queijo está bom. É o principal, porque o cliente olha o queijo e aperta. $\mathrm{O}$ cliente percebe a diferença e fala: esse queijo está mais forte, está mais ácido, isso e aquilo".

Legislação a que está submetido: normas técnicas do SIM 
Quadro 2 - Caracterização dos casos espanhóis

\section{Produtor: E1}

Município: Sevilla

Formalização: Ministério de Sanidad, Consumo y Bienestar social (AECOSAN)

Leite utilizado: Leite de cabra cru

Tipo de queijo produzido: Queijos artesanais de coagulação láctica

Volume de leite processado/dia: 80 litros

Canais de comercialização: possuem loja própria

Principais dificuldades enfrentadas para a produção de queijo: "Em 2003 a normativa espanhola não permitia fazer queijos com leite cru, com menos de 60 dias de maturação. Foi uma luta importante com o governo espanhol, para mostrar que a normativa europeia permitia".

Relações com os clientes: "Há clientes que são amigos, tem relações de confiança com a gente, vão nos visitar e podem valorar como trabalhamos".

Definição de queijo artesanal: processo manual. "É um queijo que respeita uma série de princípios. É importante para mim que haja um compromisso, e que mesmo que tu cresças, tu não pode comprometer o que tu te propõe. Sempre há um desejo de crescimento, mas até quanto? Se tem que abrir dos teus valores, para mim não é válido".

Definição de qualidade: "É um queijo honesto. E honesto não significa que é um queijo mais caro, mas sim que é um queijo que tem valor, ou seja, o que você diz que faz é o que realmente você faz. Qualidade não está ligado somente a atender padrões, mas está relacionado com compromissos sociais, ecológicos, sustentabilidade, esses valores tem que ir unidos a qualidade".

Opinião sobre a legislação sanitária: considera que houve avanços na legislação espanhola, graças à formação da Quered, associação de pequenas queijarias.

Opinião sobre a padronização do queijo: “As pequenas queijarias têm uma capacidade grande de se adaptar ao mercado, ainda os padrões que colocamos sobre qualidade são feitos por nós mesmos. Por exemplo, no meu caso, que trabalhamos com sistema extensivo de criação, leite cru, fermentos próprios, esses são os meus padrões de qualidade que eu não posso abrir mão e mudar, os demais pode mudar, o formato, o tamanho".

Legislação a que está submetido: Regulamento $n^{\circ} 852 / 2004, n^{\circ} 853 / 2004, n^{\circ} 854 / 2004, n^{\circ}$ $2014 / 2005$

\section{Produtor: E2}

Município: Castuera

Formalização: Ministério de Sanidad, Consumo y Bienestar social (AECOSAN)

Leite utilizado: Leite de ovelha cru

Tipo de queijo produzido: Queijos artesanais de coagulação láctica e enzimática

Volume de leite processado/dia: 300 litros

Canais de comercialização: venda direta na propriedade e lojas especializadas em grandes centros

Principais dificuldades enfrentadas para a produção de queijo: matéria-prima de qualidade 
Relações com os clientes: a maior venda é realizada para intermediários

Definição de queijo artesanal: "Algo artesanal é algo que se controla com os sentidos, com os olhos, tato, olfato, o processo artesanal não é $2+2=4$, como o leite é uma matéria viva, o tempo, a temperatura, depende da estação do ano, da raça, tudo muda. E o queijo artesanal depende do queijeiro, com a sua experiência, que se transmite de pai para filho".

Definição de qualidade: ter uma matéria-prima de qualidade, respeitar as etapas de processamento

Opinião sobre a legislação sanitária: "Esse tipo de legislação tem que ser diferenciada e flexível, não é o mesmo que fazer queijos em grande escala, que tem um profissional para fazer cada coisa. E numa pequena empresa uma pessoa é responsável por tudo”.

Opinião sobre a padronização do queijo: Alguns aspectos, como sabor e textura, devem ser padronizados.

Legislação a que está submetido: Regulamento $n^{\circ} 852 / 2004, n^{\circ} 853 / 2004, n^{\circ} 854 / 2004, n^{\circ}$ $2014 / 2005$

\section{Produtor: E3}

Município: Cartagena

Formalização: Ministério de Sanidad, Consumo y Bienestar social (AECOSAN)

Leite utilizado: Lei de cabra pasteurizado

Tipo de queijo produzido: Queijos artesanais de coagulação enzimática e queijo fresco de Múrcia DOP

Volume de leite processado/dia: 9.000 litros

Canais de comercialização: venda para redes de supermercados, restaurantes, delicatessens Principais dificuldades enfrentadas para a produção de queijo: qualidade e quantidade de matéria-prima

Relações com os clientes: a maior venda é realizada para intermediários

Definição de queijo artesanal: processo manual, pequena escala de produção. "Um produto artesanal está relacionado a um produto de maior qualidade. E como tu não investe tanto em maquinário, pode investir na qualidade da matéria-prima. Um produto artesanal também é um produto que não tem matéria-prima abundante".

Definição de qualidade: "Qualidade sanitária, e depois depende do tipo de queijo, a rugosidade, sabor, quantidade de sal, envase adequado, que se possa enxergar o produto (envase transparente), grãos uniformes".

Opinião sobre a legislação sanitária: "Consideramos que a legislação não é muito permissiva e nem muito restritiva, é coerente".

Opinião sobre a padronização do queijo: "Há clientes que se mudamos o mínimo detalhe do produto, vão perceber a diferença. O cliente é muito exigente. Eu acredito que é mais fácil tu criar um produto novo do que mudar um que já existe".

Legislação a que está submetido: Regulamento $n^{\circ} 852 / 2004, n^{\circ} 853 / 2004, n^{\circ} 854 / 2004, n^{\circ}$ 2014/2005, Regulamento DOP Queijo de Múrcia

Produtor: E4

Município: Cartagena 
Formalização: Ministério de Sanidad, Consumo y Bienestar social (AECOSAN)

Leite utilizado: Leite de cabra pasteurizado

Tipo de queijo produzido: Queijos artesanais de coagulação lática e enzimática Volume de leite processado/dia: 1.400 litros

Canais de comercialização: venda para redes de supermercados e lojas especializadas

Principais dificuldades enfrentadas para a produção de queijo: relatam as dificuldades inicias para começar a produzir

Relações com os clientes: a maior venda é realizada para intermediários

Definição de queijo artesanal: processo manual, sem utilização de aditivos químicos

Definição de qualidade: Qualidade da matéria-prima e não utilização de aditivos químicos

Opinião sobre a legislação sanitária: "Consideramos que a legislação não é muito permissiva e nem muito restritiva, é coerente".

Opinião sobre a padronização do queijo: é necessário manter certa padronização, pois o consumidor percebe as diferenças no produto

Legislação a que está submetido: Regulamento $n^{\circ} 852 / 2004, n^{\circ} 853 / 2004, n^{\circ} 854 / 2004, n^{\circ}$ $2014 / 2005$

Quadro 3 - Caracterização dos casos italianos

Produtor: I1

Município: Canove di Roana

Formalização: Unitá Locale Socio Sanitaria (ULLS)

Leite utilizado: Leite de vaca cru

Tipo de queijo produzido: Queijo asiago DOP e outros tipos de queijos artesanais frescos e maturados

Volume de leite processado/dia: 400 litros

Canais de comercialização: venda na propriedade (90\%), feiras e supermercados

Principais dificuldades enfrentadas para a produção de queijo: "Precisa uma mudança na cultura do consumidor, porque as pessoas estão acostumadas a comprar produtos industrializados no supermercado".

Relações com os clientes: estabelecem relações de proximidade com a maioria dos clientes, que compram com assiduidade, porém recebem também muitos turistas na propriedade

Definição de queijo artesanal: processo manual, sem utilização de aditivos químicos, receitas tradicionais

Definição de qualidade: "Nem todas as características que dão qualidade ao queijo são visíveis, mas a primeira coisa são as características sensoriais".

Opinião sobre a legislação sanitária: "Basta trabalhar bem, ter um bom leite, saudável, com uma agroindústria limpa, não tem problema".

Opinião sobre a padronização do queijo: "O queijo artesanal é sempre diferente e os consumidores percebem a diferença".

Legislação a que está submetido: Regulamento $n^{\circ} 852 / 2004, n^{\circ} 853 / 2004, n^{\circ} 854 / 2004, n^{\circ}$ 2014/2005, Regulamento Queijo Asiago DOP 


\section{Produtor: I2}

Município: Canove di Roana

Formalização: Unitá Locale Socio Sanitaria (ULLS)

Leite utilizado: Leite de vaca cru

Tipo de queijo produzido: Queijo tipo asiago e outros tipos de queijos artesanais frescos e maturados

Volume de leite processado/dia: 1.000 litros

Canais de comercialização: possuem loja própria junto a agroindústria

Principais dificuldades enfrentadas para a produção de queijo: burocracia

Relações com os clientes: conhecem os clientes que vem com assiduidade, conhecem as histórias familiares, recebem também muitos turistas

Definição de queijo artesanal: processo manual, pequena produção

Definição de qualidade: o queijo deve ter características sensoriais adequadas

Opinião sobre a legislação sanitária: tem uma opinião positiva em relação à legislação e reforça a importância do projeto PPL (Piccola Produzione Locale) que criou facilidades para a pequena produção.

Opinião sobre a padronização do queijo: "Por ser um produto artesanal não é completamente padronizado, sempre vai ser distinto. Se o queijo fosse sempre igual, eu ficaria triste".

Legislação a que está submetido: Regulamento $n^{\circ} 852 / 2004, n^{\circ} 853 / 2004, n^{\circ} 854 / 2004, n^{\circ}$ 2014/2005, regulamentos PPL

\section{Produtor: I3}

Município: Enego

Formalização: Unitá Locale Socio Sanitaria (ULLS)

Lei utilizado: Leite de vaca cru

Tipo de queijo produzido: Queijo tipo asiago e outros tipos de queijos artesanais frescos e maturados

Volume de leite processado/dia: 1.500 litros

Canais de comercialização: venda na propriedade (90\%) e venda a intermediários

Principais dificuldades enfrentadas para a produção de queijo: "As pessoas querem padronizar a qualidade".

Relações com os clientes: constroem relações de proximidade, pois vendem para vizinhos e conhecidos, há venda para turistas também

Definição de queijo artesanal: processo manual, pequena produção

Definição de qualidade: o queijo deve ter características sensoriais adequadas

Opinião sobre a legislação sanitária: exige investimentos altos na infraestrutura

Opinião sobre a padronização do queijo: "O queijo artesanal não pode ser padronizado". Legislação a que está submetido: Regulamento $n^{\circ} 852 / 2004, n^{\circ} 853 / 2004, n^{\circ} 854 / 2004, n^{\circ}$ 2014/2005, regulamentos PPL

Produtor: I4

Município: Asiago 
Formalização: Unitá Locale Socio Sanitaria (ULLS)

Lei utilizado: Leite de vaca cru e pasteurizado

Tipo de queijo produzido: Queijo asiago DOP e outros tipos de queijos artesanais frescos e maturados

Volume de leite processado/dia: 26.000 litros

Canais de comercialização: possuem 2 lojas próprias, vendem para grandes redes e representações e fazem exportação

Principais dificuldades enfrentadas para a produção de queijo: comercialização

Relações com os clientes: nas lojas próprias constroem relações de proximidade

Definição de queijo artesanal: processo manual

Definição de qualidade: ter sanidade e sabor

Opinião sobre a legislação sanitária: "Há coisas para melhorar, a lei para a pequena produção artesanal foi imposta e exige muitas análises".

Opinião sobre a padronização do queijo: "Para a distribuição é importante, mas cada forma é diferente, o que é símbolo da produção artesanal. Se todos fazem a mesma coisa, vira uma commodity".

Legislação a que está submetido: Regulamento $n^{\circ} 852 / 2004, n^{\circ} 853 / 2004, n^{\circ} 854 / 2004$, $n^{\circ}$ 2014/2005, Regulamento Queijo Asiago DOP

\section{CONSIDERAÇÕES FINAIS}

O conceito de queijo artesanal parece estar mais fortemente relacionado à pequena escala de produção, ao predomínio de processamento manual e ao não uso de aditivos químicos, do que outros critérios. Assim podemos pensar que são artesanais tanto os queijos chamados de tradicionais, aqueles relacionados à origem geográfica, baseados em receitas passadas de geração em geração, como aqueles queijos que surgem a partir da inovação do queijeiro.

Não há dúvidas quanto à importância da qualidade do leite utilizado, principalmente quando do uso de leite cru, sendo menos relevante o leite ser de produção própria, ou ser adquirido de terceiros.

A padronização na produção artesanal é pertinente no controle higiênico-sanitário, porém há que se considerar que os demais parâmetros como sabor, textura, cor e formato podem variar de acordo com a época do ano, devido às mudanças de clima e de alimentação dos animais - além da variação da microbiota presente no leite cru - e pelo fato de grande parte do processamento ser manual.

A importância da venda direta e do estabelecimento de relações de proximidade entre produtores e consumidores ficou evidente em todos os países estudados. A comunicação entre o produtor e o consumidor permite a troca de informações e conhecimento e permite a formação de laços de confiança, que muitas vezes são a razão da compra de produtores informais.Porém, no Brasil os consumidores parecem não ter uma visão clara das diferenças entre uma produção artesanal e industrial e das características que se deve esperar desse tipo de alimento.

O que se pode verificar em relação aos países europeus estudados é que eles possuem consumidores mais conscientes, legislações mais adequadas e os produtores têm uma visão conjunta do setor. Mas é preciso destacar também que problemas normativos e mesmo de interpretação também existem nesses países. 


\section{AGRADECIMENTOS}

Aos produtores de queijo, EMATER/ RS-Ascar e CAPES.

\section{REFERÊNCIAS}

\section{ASIAGO FORMAGGIO DOP. Disciplinare} di produzione DOP “Asiago". Vicenza, Itália, 2019. Disponível em: https://www. asiagocheese.it. Acesso em: 8 fev. 2019.

BRASIL. Ministério da Agricultura, Pecuária e Abastecimento. Portaria $n^{\circ} 146$, de 7 de março de 1996. Aprova os regulamentos técnicos de identidade e qualidade dos produtos lácteos. Diário Oficial da União, seção 1, Brasília, DF, p. 3977, 11 mar. 1996.

BRASIL. Ministério da Agricultura, Pecuária e Abastecimento. Instrução Normativa $n^{\circ}$ 30, de 07 de agosto de 2013. Permite a produção de queijos artesanais elaborados a partir de leite cru. Diário Oficial da União, seção 1, Brasília, DF, p. 19, 08 ago.2013.

CRUZ, F. T.; MENASCHE, R. O debate em torno de queijos feitos de leite cru: entre aspectos normativos e a valorização da produção tradicional. Vigilância Sanitária em Debate, v. 2, n. 4, p. 34-42, 2014. DOI: 10.3395/VD.V2I4.408.

DIAS, V. V. Lealdade e relações de proximidade: uma caracterização dos consumidores de alimentos orgânicos. 2016. 279f. Tese (Doutorado em Agronegócios) - Centro de Estudos e Pesquisas em Agronegócios, Universidade Federal do Rio Grande do Sul, Porto Alegre, 2016.

EYMARD-DUVERNAY, M. F. Conventions de qualité et formes de coordination. Revue Économique, v. 40, n. 2, p. 329-359, 1989.
GONZÁLEZ-CÓRDOVA, A. F. et al. Invited review: Artisanal Mexican cheeses. Journal of Dairy Science, v. 99, n. 5, p. 3250-3262, 2016. DOI: $10.3168 /$ jds.2015-10103.

GOODMAN, D. The quality 'turn' and alternative food practices: reflections and agenda. Journal of Rural Studies, v. 19, p. 1-7, 2003. DOI: 10.1016/S0743-0167 (02)00043-8.

GOODMAN, D. Rural Europe Redux ? Reflections on alternative agro-food networks and paradigm change. Sociologia Ruralis, v. 44, n. 1, 2004. DOI: 10.1111/j.14679523.2004.00258.x.

GRUNERT, K. G. Food quality and safety: Consumer perception and demand. European Review of Agricultural Economics, v. 32, n. 3, p. 369-391, 2005. DOI: 10.1093/eurrag/ jbi011.

KNOLL, L. P. Origins of the regulation of raw milk cheeses in the United States. Cambridge, 2005. Online. Disponível em: http://nrs. harvard.edu/urn-3:HUL.InstRepos:8852188. Acesso em: 24 nov 2018.

LICITRA, G. World wide traditional cheeses: Banned for business? Dairy Science \& Technology, v. 90, n. 4, p. 357-374, 2010. DOI: $10.1051 / \mathrm{dst} / 2010016$.

NICHELE, F. S.; WAQUIL, P. D. Agroindústria familiar rural, qualidade da produção artesanal e o enfoque da teoria das convenções. Ciência Rural, Santa Maria, v. 41, n. 12, p. 2230-2235, 2011. DOI: 10.1590/S010384782011001200030 .

NIEDERLE, P. A. Economia das Convenções: subsídios para uma sociologia das instituições econômicas. Ensaios FEE, v. 34, n. 2, p. 439-470, 2013. 
PARLAMENTO EUROPEO Y DEL CONEJO. Reglamento (CE) n ${ }^{\circ} 852 / 2004$ del Parlamento Europeo y del Consejo de 29 de abril de 2004, relativo a la higiene de los productos alimenticios. Jornal Oficial da União Europeia. Bruxelas, 2004a. Disponível em: https://eur-lex.europa.eu/legal-content/ ES/TXT/?uri=LEGISSUM\%3 Af84001. Acesso em: 30 nov. 2018.

PARLAMENTO EUROPEO Y DEL CONSEJO. Regulamento (CE) $n^{\circ} 2074 / 2005$ da Comissão de 5 de dezembro de 2005, que estabelece medidas de execução para determinados produtos ao abrigo do Regulamento (CE) $n^{\circ} 853 / 2004$ do Parlamento Europeu e do Conselho e para a organização de controles oficiais. Jornal Oficial da União Europeia, p. 27-60. Bruxelas. 2005. Disponível em: https://eur-lex.europa.eu/homepage.html. Accesso em: 30 nov. 2018.

PARLAMENTO EUROPEU Y DEL CONSEJO. Reglamento (CE) $n^{\circ} 854 / 2004$ del Parlamento Europeu y del Consejo, de 29 de abril de 2004. Jornal Oficial da União Europeia. Bruxelas, 2004b. Disponível em: https://eur-lex.europa.eu/homepage.html. Accesso em: 30 nov. 2018.

PARLAMENTO EUROPEO Y DEL CONSEJO. Regulamento (CE) $n^{\circ} 853 / 2004$ do Parlamento Europeu e do Conselho de 29 de abril de 2004. Jornal Oficial da União Europeia. Bruxelas, 2004c. Disponível em: https://eur-lex.europa.eu/homepage.html. Accesso em: 30 nov. 2018.

PICCOLE PRODUZIONI LOCALI. ALLEGATO A DGR no 2.162, del 29 dicembre 2017. Vêneto. 2017. Disponível em: https://www.pplveneto.it/. Accesso em: 23 jan. 2019.

PONTE, S. Convention theory in the An- glophone agro-food literature: Past, present and future. Journal of Rural Studies, v. 44, p. 12-23, 2016. DOI: $10.1016 / \mathrm{j}$. jrurstud.2015.12.019.

POZNANSKI, E. et al. Indigenous raw milk microbiota influences the bacterial development in traditional cheese from alpine natural park. International Journal of Food Microbiology, v. 92, n. 2, p.141-51, 2004. DOI: 10.1016/j.ijfoodmicro.2003.09.006.

QUERED. Red española de queserías de campo y artesanas. Disponível em: https:/www. redqueserias.org/. Accesso em: 7 fev. 2019.

SEIXAS, V. N. C. et al. Socioeconomic diagnosis of cheese producers of Marajó , state of Pará, Brazil. Revista do Instituto de Laticínios Cândido Tostes, v. 69, n. 5, p. 309-321, 2014.

STAMER, N. B. Moral conventions in food consumption and their relationship to consumers' social background. Journal of Consumer Culture, v. 18, n. 1, p. 202-222, 2018.

STEENKAMP, J.-B. E. M. Conceptual model of the quality perception process. Journal of Business Research, v. 21, n. 4, p. 309-333, 1990.

VIEIRA, L. M. et al. An analysis of value in an organic food supply chain. British Food Journal, v. 115, n. 10, p. 1454-1472, 2013.

YIN, R. K. Estudo de caso - planjemaneto e métodos. $2^{\mathrm{a}}$ ed. Porto Alegre: Bookman, 2001.

ZUMBO, A. et al. Ripening-induced changes in microbial groups of artisanal Sicilian goats' milk cheese. Italian Journal of Animal Science, v. 8, n. SUPPL. 2, p. 450-452, 2009. 